\title{
Michael Eldred:
}

\section{Reputation in the Cyberworld}

\begin{abstract}
:
The article explores the socio-ontological foundations of the phenomenon of reputation in the context of today's ever-encroaching cyberworld. The categories of whoness and value are essential for understanding reputation ontologically. The cyberworld itself has only become historically possible through the Cartesian mathematical cast of being and its digital refinement in the Universal Turing Machine. From one perspective, the cyberworld is an endless concatenation of Turing machines. It is, however, also a matrix in which bit-strings circulate that have a decisive impact on who anybody is held to be by others, i.e. on their reputation. The game of striving to be esteemed as who you are thus assumes a new complexion in the digital era.
\end{abstract}

\section{Agenda:}

Who you are 6

Estimating, esteeming, evaluating, valuing who you are 6

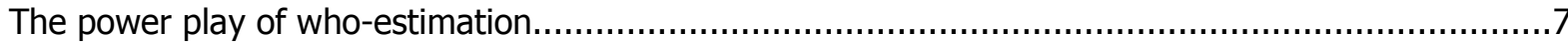

Digitized identity

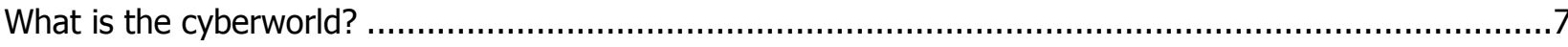

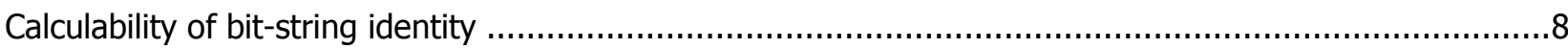

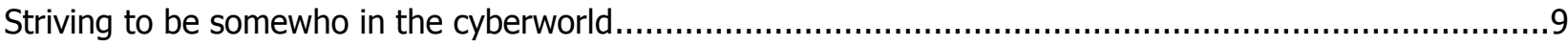

Vicissitudes of reputation in the cyberworld ..................................................................

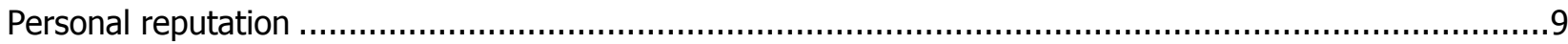

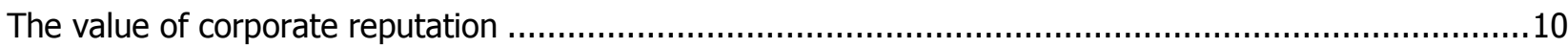

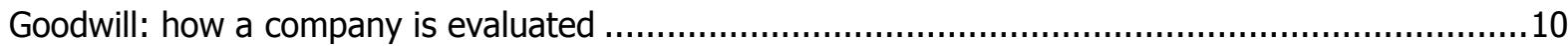

\section{Author:}

Dr. Michael Eldred:

- $\quad$ artefact text \& translation, Antwerpener Str. 1, D-50672 Cologne, Germany

- 畺 +49 - 221 - $9520333 \bowtie$ me@arte-fact.org $\square$ www.arte-fact.org

- Relevant publications:

- Digital Whoness: Identity, Privacy and Freedom in the Cyberworld (with R. Capurro \& D. Nagel) Frankfurt: ontos verlag 2013, 312 pp.

- The Digital Cast of Being: Metaphysics, Mathematics, Cartesianism, Cybernetics, Capitalism, Communication Frankfurt: ontos verlag 2009, 137 pp.; emended, revised and extended e-book edition, Version 3.0, 2011215 pp. available at www.arte-fact.org 
- Social Ontology: Recasting Political Philosophy Through a Phenomenology of Whoness Frankfurt: ontos verlag 2008, xiv + 688 pp.; second revised, emended and extended e-book edition, Version $2.12011,785$ pp. available at www.arte-fact.org 
This article offers some fundamental philosophical clarification of reputation on the basis of a phenomenology of whoness. The ontology of the cyberworld will be sketched, and the phenomenon of reputation, both personal and corporate, situated within this context. ${ }^{1}$

\section{Who you are}

Who are you is not a trivial question. It is a socio-ontological question concerning your presencing and absencing in the time-clearing of the world. Who you are, is said here in the second grammatical person, who I am, is said in the first person, who he or she is, is said in the third person singular, and who they are, is said in the third person plural. These grammatical persons, too, are not trivial taxonomic matters of grammar; rather, each is a phenomenon of presencing in its own right calling for reflection. The question concerning who you are is to be distinguished from the traditional metaphysical question as to what something is, posed in the third person singular. Whereas the question concerning whatness (essence, quiddity, substance) has a venerable history going all the way back to Plato and Aristotle, the explicit, emphatic question concerning whoness (quissity) is relatively recent, arising in the wake of Ludwig Feuerbach. ${ }^{2}$ Martin Heidegger brings in a new twist by explicitly posing the question concerning whoness (Wersein, Werheit) in the $1920 \mathrm{~s}^{3}$ which in turn was taken up in a different vein by Hannah Arendt in her opus magnum, The Human Condition ${ }^{4}$ and also by myself, again in a different vein, in various works. ${ }^{5}$

Heidegger uncovered the underlying meaning of being implicit throughout Western thinking to have been presence. To be who you are is to be present in the world, which is itself fundamentally temporal, namely, the three-dimensional time-clearing of past, present and future in which you present and absent yourself, showing yourself off as who are, including also privative modes of concealing (certain aspects of) who you are. In the case of whos, presence in the world is always also a self-presenting, of showing-off.

\section{Estimating, esteeming, evaluating, valuing who you are}

It is essential for showing-off to have yourself acknowledged by others as who you show yourself to be. You choose, or neglect to choose, your masks for self-display in adopting this or that behaviour and views, wearing certain clothes rather than others, etc. The interplay with each other is always a reciprocal estimating of each other's self-presentations. You present yourself as some who or other, thus making a certain impression on others. Who you are is always a matter of having adopted certain masks of identity reflected from the world as options for who you could be in the world. Each human being is an origin of his or her own self-movements and has an effect on the surroundings, changing them this way or that, intentionally or unintentionally. Being estimated positively in presenting yourself to others is the phenomenon of esteem. Such esteeming, evaluating estimation of your self-presentation depends also on presenting, or at least seeming to present, yourself as a capable who in some sense or other, which will be estimated variously in different circles and situations.

\footnotetext{
${ }^{1}$ This article draws on my contributions to Capurro/Eldred/Nagel 2013.

${ }^{2}$ And on through authors such as Martin Buber, Eugen Rosenstock-Huessy, Ferdinand Ebner, Eberhard Grisebach, Karl Heim, Gabriel Marcel, Friedrich Gogarten, Helmut Plessner, Adolf Reinach, Dietrich von Hildebrand, Wilhelm Schapp, Alfred Schütz, Ludwig Binswanger, Karl Löwith, Hermann Levin Goldschmidt and Emmanuel Lévinas; cf. Theunissen, Michael 1977 for a comprehensive overview of most of these authors.

${ }^{3}$ Cf. e.g. Heidegger, Martin 1927, 1975.

${ }^{4}$ Arendt, Hannah 1958.

${ }^{5}$ Eldred, Michael 1989, 1999, 2008.
} 


\section{The power play of who-estimation}

The core mask of identity borne by a who is one's own proper name, around which other masks cluster. Above all, it is a matter of adopting masks of ability reflected by the world, thus developing your own potential abilities into developed personal powers of whatever kind. Each who ends up in some vocation, profession, job, social role or other, thus becoming who she or he is in living that cast role, and this is the mask of identity that somewho, for the most part, presents to the world as who he or she is, being estimated and esteemed by the others in the interplay. Since human beings are estimated and esteemed as who they are above all on the basis of their personal powers and abilities, and because the exercise of such powers also effects some change or other in the world, the interplay of mutual estimation is always also a power play, especially in the sense of mutually estimating each other's who-status. At first and for the most part, you wish to have your developed powers and abilities, whatever they may be, esteemed by the others in the power play. You may fail in doing so. In sharing the world, human beings are constantly estimating and evaluating each other's performances in presenting themselves as somewho or other through their powers and abilities, i.e. their merit, as that which deserves esteem. Those of a similar who-standing are therefore, for the most part, in a competitive rivalry with one another.

The individual powers and abilities you have adopted as masks of identity widens the focus from the temporal mode of presence because such powers refer both to who you have already become and also to who you may become in future. The estimation of your abilities by the others gives rise to your reputation as who you are, and reputation refers to how you have presented yourself to the world in the past, which is never past, because you have inevitably always already established or ruined your reputation as who in some circle or other. Conversely, who you will become depends crucially also on your potential being estimated by those who are in a position (especially parents and teachers) to foster the development of that potential to powers and abilities that an individual actually has at its disposal. Furthermore there is the futura/aspect of whoness in the ambition that you have to be cast in a certain who-role, usually by honing your abilities of whatever kind. Such ambition is always also linked to as who you want to be regarded in the world and is thus tied intimately to the power play of mutual estimation. Ambition is the striving to leave your mark on the world, even to the point of establishing your fame as someone about whom the 'world' speaks. Leaving your mark on the world is a way of making an impression on the shared world, namely, a lasting impression, which again refers to the temporal dimension of the past or 'beenness'.

Wanting to make any impression at all on the world, let alone, wanting to have an impact or to leave your mark on the world, are all manifestations of the will to power to be who. To be somewho in the world amounts to having your self-presentation to the world estimated, esteemed and reflected by the world, to come to stand in shared presence as a who with some standing. Such standing presence, however, is very fragile in the power play of togetherness in general, for it depends on the mirror game of mutual self-presentation in which having a stand as who depends on the reflections of estimation received back from the others. Appreciative reflections of esteem from the others may be very fickle, easily replaced by depreciative, even downright derogatory, reflections. This contrasts with traditional metaphysical determinations of whatness which is a standing presence either in the sense of possessing an enduring, well-defined essence, or in the sense of possessing an underlying, enduring substance that persists in presence. Whoness as a mode of presencing is the way in which human beings share a world with each other, i.e. the mode of mutually mirroring togetherness in the timespace of the world. Such presencing as somewho in an ongoing power play of mutual estimation is insubstantial, that is, lacking an underlying substrate, and is thus groundless.

\section{Digitized identity}

\section{What is the cyberworld?}

Cyberworld is the name not for some merely ontic-factual, artificial thing, but the existential-ontological name for the ontic-factual internet plus other interlinked networks insofar as this global technical thing also represents 
an (electromagnetic) medium for the movement of digital beings (bit-strings) in which we human beings participate and through which we also steer, either directly, or indirectly through automatically executable digital code. This gives rise, say, to the possibility of robots, which are artificially 'animated' machines that, once programmed, have the source of movement within themselves, even though they need a current of electrons to drive them.

The cyberworld, as the materialization of the digital cast of being, ${ }^{6}$ is an artificial world produced by outsourcing the arithmologos as (executable, automatic) digital code that moves in its own global medium. It is populated by countless trillions of bit-strings that are either 'passive' digital data or 'active' executable program code. These two kinds of code copulate with each other in countless billions of Universal Turing Machines, ${ }^{7}$ generating new bit-strings that continue to circulate throughout the cyberworld, which itself is nothing other than a neverending concatenation of Universal Turing Machines impregnated in the electromagnetic matrix. Digital beings are nothing but digital code, i.e. strings of bits. A bit is pure binary difference that can be represented by, say, 1 and 0 . To write a bit, a stable difference in the inscription matrix between two unambiguous states is required, and this is provided by electromagnetic states of the medium that can be changed in a controlled way by electromagnetic force fields, including currents of electrons, photons or laser beams. Digital program code must be 'legible' to a processor as a set of step-by-step instructions (the algorithm) about what to do with digital data input. After processing, other bit-strings are output, which are signals sent to destinations to trigger electromagnetic effects.

As far as the human user or denizen of the cyberworld is concerned, the cyberworld presents itself to him or her through the various interfaces that today have been well-adapted to the human body and mimic the physical world. Such interfaces are technical, requiring a technical device of some sort: desktop, laptop, hand-held, implanted chip or whatever. This device itself is assigned a number automatically (e.g. IP address) by the cyberworld; it is identifiable through this number, which may be combined with other numbers such as location and time co-ordinates. The human user of a digital device interfaced with the cyberworld is willy-nilly identified with this device's number so that, in a certain way, the user's identity itself becomes this number as far as his or her presence in the cyberworld goes. A cyberworld denizen can call up data from all over the world, according to his or her interests, which are a reflection of personal identity, i.e. of who this individual understands himor herself to be in the world. A cyberworld denizen can also present him- or herself as who $\mathrm{s} / \mathrm{he}$ is by posting data at some site within the cyberworld. These data, of whatever kind (text, image, sound, video) are identified with the individual posting them, who may or may not use a pseudonym.

\section{Calculability of bit-string identity}

Because all sorts of data circulating in the cyberworld can easily be stored, i.e. recorded automatically, this opens up many opportunities for processing those data, in particular, with a view to establishing the identity of a particular user and his or her life-movements. The individual is identified with a piece of code (an IP address, the ID of a digital device, etc.) that enables also cyber-surveillance and cyber-tracking, amounting to 'überveillance'. ${ }^{8}$ All the digital data in the cyberworld relating to a certain individual can be pieced together, through the appropriate executable code, in an individual profile that inverts the first-person perspective of what someone does in the cyberworld into a third-person perspective of a reified digital data profile through which others, in a certain way, have disposal over who the individual concerned is. The cyberworld is a cyber-space-time with digitized Cartesian space-time co-ordinates recording movements within it, and not the time-clearing of a world in which human being exists ec-statically stretched toward three independent temporal dimensions. ${ }^{9}$ Hence the third-person, 'objective', 'scientific' view of an individual that is enabled through the linking of digital data,

\footnotetext{
${ }^{6}$ Cf. Eldred 2009/2011.

${ }^{7}$ Cf. Eldred 2012a.

${ }^{8}$ Cf. Michael \& Michael 2010.

${ }^{9}$ Cf. Eldred 2009/2011 for more on three-dimensional, ecstatic time.
} 
clashes with the first-person view of an individual living his or her life in and out of the cyberworld or the firstand-second person viewpoints of sharing a world. ${ }^{10}$

\section{Striving to be somewho in the cyberworld}

The striving of any who to be somewho in the cyberworld is to receive as much appreciative feedback from other cyberworld denizens as possible, which can happen fairly directly due to the cyberworld's accessibility to everybody. In the case of other public media, there is usually a gatekeeper that watches over who is to have a say, to make an appearance in that medium. The who-game thus comes to be played on a larger, global, digitally mediated scale, a cyber-stage. Nevertheless, the stakes remain, firstly, being noticed at all, and, secondly, gaining others' attention, being esteemed and estimated highly by others (positive feedback). What Plato called 'love of esteem' thus takes on a different garb in a different scenario in the digital age, but remains the same in that it is still the who-game which, of course, is played not only in the West. The lure of being esteemed as somewho is amplified by the ease of self-presentation in the cyberworld.

Another aspect of finding one's self in the cyber-era is that, due to its global reach, the cyberworld reflects many different possibilities of living in the world, from all the world's different cultures. Ease and cheapness of access to the internet for billions of people open up a vast space in which to find one's self, thus perhaps causing friction with the expectations within the ethos of a given culture. Especially entertainment media such as film and music proffer identity masks to anyone who'll put them on, adopting a life-style and self-understanding that may be promoted by a culture industry. The ease with which digital beings disseminate throughout the cyberworld leads to a fast merging of possible identities, especially for youth who are still finding themselves, also in what the cyberworld offers by way of quickly circulating identity masks that inevitably induce also a certain levelling of youth-identity. One of the more trivial of such masks is fashion, i.e. how somewho dresses to present him- or herself to the world. With the cyberworld, youth fashion especially spreads very quickly around the globe, with youth fashion strategies demarcating who one is from one's parents' identities becoming adopted rapidly. The typical different local cultural identities also become more visible in their differences via the cyberworld.

\section{Vicissitudes of reputation in the cyberworld}

\section{Personal reputation}

With the digitization of identity in the cyberworld, one could say that the genie is out of the bottle. Once who you are has become a set of bit-strings circulating in the global electromagnetic medium, who you are held to be by others, i.e. your reputation, becomes a matter of interpreting and evaluating those bit-strings identified with you. These identity bit-strings are the traces of your presence and movement through the cyberworld, and these traces remain - unlike many traces of your life-movements in the physical world - and accumulate in the electromagnetic matrix. Such digital traces, in turn, can be gathered and processed by other bits of executable digital code, i.e. they can be input into yet another Turing machine which mines those data either generally or specifically. Market research, for instance, is interested in mining personal data for the sake of assessing your potential as a consumer in a certain market segment, whereas a prospective employer may be interested in your personal reputation as represented by your cyberworld presentation of yourself over time. In particular, your vocational reputation as presented by circulating bit-strings will influence how potential customers and clients will evaluate you, or whether a potential employer will hire you. No bit-string with an identity-link to you is therefore innocent, and its longevity in the cyberworld means that it may be taken up and re- and misinterpreted in later contexts. After all, who you are and held to be by others is always a matter of interpretation in which certain bit-strings are understood as such-and-such, i.e. the hermeneutic As is always

${ }^{10}$ Cf. Capurro 2011. 
operable. Via stored bit-strings, your identity from the past may be resuscitated with either beneficial or deleterious, fair or unfair results. The options for recasting yourself at a later stage of life after your past reputation has been 'forgotten' alter with the calculating potentials of the cyberworld that retrieves with ever more powerful executable digital code who you have been.

With the onset of the cyberworld, who you are in the world, i.e. your being, becomes an identity with something different from you, namely, a certain set of bit-strings circulating in the interconnected global electromagnetic medium, whose interpretation amounts to the third-person reputation you have in the world as a whole. This is a qualitatively new level of reification of your reputation beyond the estrangement from your personal identity already introduced with the advent of mass media in the $19^{\text {th }}$ and $20^{\text {th }}$ centuries. Who you are held to be, and consequently, how you are esteemed and valued, becomes in part a function of how certain bit-strings are interpreted and evaluated. In certain cases it may become necessary for you to defend yourself legally, so far as possible, against libel, slander and calumny that denigrate your who-status. In this way, you may even be drawn into Joseph K.'s nightmare as Kafka eerily unfolds in The Trial (Der Prozeß), which opens with the line:

"Someone must have slandered Joseph K., for one morning, without his having done anything bad, he was arrested." 11

\section{The value of corporate reputation}

The dimensions of the reification of reputation expand when considering non-natural, juridical persons, including commercial companies. Any corporate entity will be jealous of its reputation because it has a direct link to commercial success. The growing phenomenon of Corporate Social Responsibility evidences how important a company's standing in the community and society has become, including for the bottom line. Companies' reputations have long since been drawn into political struggles over fair corporate practices. This is well-known and the stuff of daily news. But what are the socio-ontological underpinnings of this now familiar phenomenon? The crux is that a juridical person such as a commercial company is not merely a what that can be considered simply as an organization in terms of, say, its efficiency, but a who. Whoness as a fundamental socio-ontological category is tied to value, esteem, estimation (timh/), i.e. to phenomena already central for Plato and Aristotle and then throughout the Western tradition. ${ }^{12}$ The essential feature of a capitalist economy is that it is mediated through and through by the movement, the circulation of reified value that, in this movement, successively assumes and strips off various value-forms such as commodities, money, productive capital, loan-capital. Through an augmentative circulation of value, each and every commercial enterprise is out for gain. The essence of capitalist economy can therefore be termed the "gainful game". ${ }^{13}$

\section{Goodwill: how a company is evaluated}

A capitalist enterprise is valued not only via the commodity goods and services it offers on the market, but also through its corporate reputation as a profit-making entity. How a company is perceived, i.e. estimated and esteemed, in the public domain affects also how well it does in gainful activity. Moreover, any going concern well-established in the market-place has a reputation which, as fictitious capital, ${ }^{14}$ has a certain value that can even be monetized, i.e. transformed into reified value, upon selling the company. This value-portion is the company's goodwill, which is estimated regularly in the company accounts and realized when the company is merged or acquired. Apart from this, any company listed on the stock exchange is factually valued every day and every second by its market capitalization which is affected, among other things, by the news-feed about

\footnotetext{
11 "Jemand mußte Josef K. verleumdet haben, denn ohne daß er etwas Böses getan hätte, wurde er eines Morgens verhaftet." Kafka 1958 p. 7.

${ }^{12}$ Cf. for details Eldred 2008/2011 esp. Chaps. 2 and 5.

${ }^{13}$ Cf. for details Eldred 2000/2010 esp. Chap. 7.2.

${ }^{14}$ Cf. for details Eldred 1984/2010 § 20 ,The Firm as Fictitious Capital. Goodwill'.
} 
the company's activity, including those that enhance or depreciate its corporate reputation. For instance, negative news-feed about a multinational's supply-sourcing in a developing country can greatly damage corporate reputation and hence also market capitalization. The company's economic goodwill diminishes. Thus, a company's who-status, too, has a reified value that is constantly being evaluated by the stock market as a whole, and this reified stock-market evaluation depends also on the good will exhibited toward the company in the public domain. The cyberworld with its circulating bit-strings relating to a given company and its activities, its market strategies, corporate policies, etc. today has a decisive impact on corporate reputation. No company of any size can afford to ignore how it is held to be, and thus estimated and evaluated, by the flow of bit-strings pertaining to it. This calls forth the necessity of measures to enhance and defend corporate reputation, such as public relations officers, corporate philanthropic activities, corporate governance policies and statements, etc. Thus even, and especially, huge and mighty companies are drawn into and subjected to the evaluations coursing through the cyberworld.

\section{References}

Arendt, Hannah The Human Condition 2nd ed. with an introduction by Margaret Canovan, Chicago U.P. 1998, 1 st ed. 1958.

Capurro, Rafael 'Never Enter Your Real Data' International Review of Information Ethics Vol. 162011 pp. 7478. URL: wWw.capurro.de/realdata.htm/

Capurro, Rafael, Michael Eldred \& Daniel Nage/ Digital Whoness: Identity, Privacy and Freedom in the Cyberworld Frankfurt: ontos verlag 2013.

Eldred, Michae/Critique of Competitive Freedom and the Bourgeois-Democratic State: Outline of a Form-AnaIytic Extension of Marx's Uncompleted System Copenhagen: Kurasje 1984, e-book edition www.artefact.org 2010. With an extensive bibliography.

Eldred, Michae/ Der Mann: Geschlechterontologischer Auslegungsversuch der phallologischen Ständigkeit Frankfurt: Haag + Herchen 1989.

Eldred, Michae/ Phänomenologie der Männlichkeit: kaum ständig noch Dettelbach: Röll 1999; e-book edition www.arte-fact.org

Eldred, Michae/Kapital und Technik: Marx und Heidegger Dettelbach: Röll 2000; english version in Left Curve No. 24, May 2000; www. arte-fact.org Ver. 3.02010.

Eldred, Michae/Social Ontology: Recasting Political Philosophy Through a Phenomenology of Whoness Frankfurt: ontos 2008; 2nd emended, revised, extended e-book edition www.arte-fact.org 2011. With an extensive bibliography.

Eldred, Michae/The Digital Cast of Being: Metaphysics, Mathematics, Cartesianism, Cybernetics, Capitalism, Communication Frankfurt: ontos verlag 2009, 137 pp.; emended, revised and extended e-book edition, Version 3.0, 2011 www. arte-fact.org With an extensive bibliography.

Eldred, Michae/ Out of your mind? Parmenides' message www.arte-fact.org Ver. 1.0 2012.

Eldred, Michael 'Turing's cyberworld of timelessly copulating bit-strings' www.arte-fact.org Ver. 1.02012 . Kafka, Franz Der Prozeß Frankfurt: Fischer 1958.

Heidegger, Martin Sein und Zeit Tübingen: Niemeyer 1927, 15th ed. 1984.

Heidegger, Martin Die Grundprobleme der Phänomenologie Marburger Vorlesung SS 1927 Gesamtausgabe Band 24 (GA24) ed. F-W. v. Herrmann, Frankfurt/M.: Klostermann 1975 English translation: The Basic Problems of Phenomenology Indiana U.P. 1982.

Michael, G.M. \& Katina Michael 'Toward a State of Überveillance?'Technology \& Society Vol. 29 No. 22010 pp. 9-16.

Theunissen, Michae/ Der Andere: Studien zur Sozialontologie der Gegenwart 2nd ed. Berlin/New York: W. de Gruyter, 1977. 